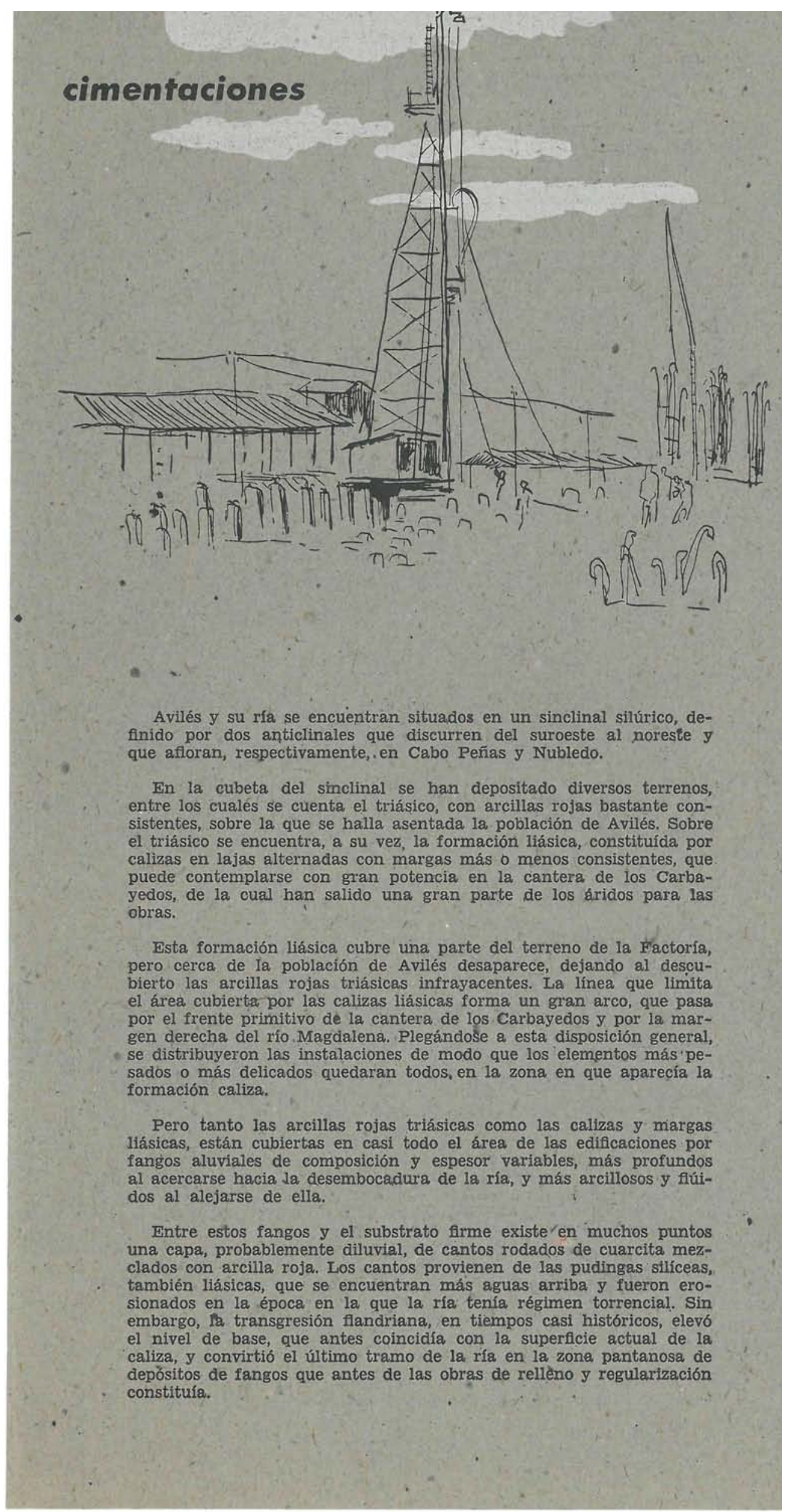


: La existencia de estos fangos complicó notablemente la construcción de las cimentaciones. Inicialmente se estudió la posibilidad de cimentar directamente sobre lós_mismos, al menos alguna parte de los elcmentos de la Factoria, para lo cual se hicieron numerosos son-deos con tóma de muestras inalteradas, en las que se efectuaron los ensajos correspondientes paia determinar sus características de resistencia y. compresibilidad.

Los resultados de estos ensayos pusieron de manificsto una gran heterógeneidad en casi toda el área, con muchos lentejoncs de arcilla bastante pura, y otras veces con-materia orgánica y hast. turbosos, correspondicndo a las trazas de Ios cursos mcandrinosos que los dis-

- tintos rios que à la ría afluyen habian jo adoptando dirante elvlargo proceso de relleno. Esta heterogeneidad implicaba la posibilidad de grandes asientos desiguales, lo cual hizo abandonar en forma general la idea de cimentación directa sobre el fango. Sin embargo se conservó parà algunos casos especialcs, como son, por ejemplo, en las áreas de colocación de pilas de carbón o mincral.

Con todo, aún en estas áreas, el asiento probable era tan importante que no podría por menos de provocar desperfectos en otras estructuras anejas, $y$, en particylar, en las tias de los pórticos de manutención. Adęmás, cuando sé trató de pilas de mineral. el pro- blema ya no era tan sólo de asientos; sino que la resistencia del fango al esfucrzo coitante cra insuficiente, $y$ se hubiera producido el hundimiento de la pila misma en el terreno... .

Por ello se recurrio al procedimiento 'de carga ṕrevia, sobrccargando el árca de antemano con presiones crecientes, de modo que fucra:experimentando grạn partc do su asiento definitivo $\mathrm{y}$, al mismo ticmpo, consolidando y aumentando su resistencia. Pero este próccso, en alguños casos, hubicra, llevado un tiempo' incompatible con las ${ }^{\circ}$ necesidades de la obra, por lo cual se recurrió a- la. construcciọn de díenes verticales de arena, anteriormente a la aplicación de la carga;sicndo ésta la segunda vez que se utilizó este procedimiento de consolidación acelcrada en España y la primera en la que se construyeron los drenes por hinca con machina de una tubería piloto y ap. sonado de la arena con aire comprimido.

- Aparté de estos casos particulares, en los que los asientos tolerables eran de cicrta importancia, las estructuras se cimentaron en el terreno firme, atravcsando-pará ello-a fangos, opefación en la que se cmplcaron procedimientos variados busç̨ndo la mejor adecuación y economía en cada caso. En èstas consideraciones'influian-las cargas a soportar, cl destino y disposición final de la infraestructura, la importancia intrínseca de cada elemento y las consecuencias que su fallo ppdía acarrear en la explotación y-de manera muy importante-el espesor de la capa de fango y laş características de éste.

Para precisár cstos extremos se hicieron 700 sondeos, muchos de ellos con toma de muestras inalteradas, sobre las cuales se efectuaron numerosos ensayos de 'laboratorio, determinando sus limites' de 'Atterbeǵ, granulometría, consistencia, compresibilidad $y$ resistencia al esfuerzo cortantc, asi como su contenido en sales $y_{\text {a }}$ materias orgánicas.

Dc todos los estudios realizados, se llegó a la coñelusión. de que lós elementos que produơian grandes cargast concentradas debian ser
cimentados sobre cajones hincados por medio de aire comprimido, exccpto en aquellas áreas-escasas-en las que la poca profundidad de - los fangos permitía el uso del cajón indio con excavación abierta. El . empleo de cajones era particularmente recomendabic en lós elementos claves, que, de sufrir un asiento, hubierain comprometido gravemente todo el proceso -de explotación de la Factoría.

En otros casos se utilizaron, con profusión, los pilotes prefabrícados', y también, en menor escala; los pilotes moldeados "in situ". Tanto uno como otro sistema resultaba dar una garantía menor que el de cajones, a causa de la hetcrogeneidad de la formación caliza liúsica,

- con alternáncía absolutámente errátjca de calizas y margas, típica de su. facies cpicontincntal, por lo cual nunca podría asegurarse si el pilote" descansaba sobre un estrato importante de caliza o sobre una laja cubriçndo un lentejón de marga.

P̂or todo ello el sistema de pilotaje se empleó en los elementós de menor responsabilidad $\mathrm{y}$-menos cargados, siendo el resultado satisfactorio.

Mérecen mención especial las cimentaciones eféctuagás. sobre, la ' zona próxima al puérto, donde el substrato cálizo hía desaparecido. 
Allí donde las arcillas rojas del triásico casi afloraban, como ocurrió en la margen izquierda de la ría, se empleó la cimentación directa (edificio de laboratorio, horno piloto, etc.), pero en la margen derecha el espesor del fango era el máximo dentro del área ocupada por la Factoría, por lo que era necesario atravesar con procedimientos costosos la espesa capa de fango para poder llegar después a un terreno cuya capacidad soportante era bastante limitada.

Como consecuencia de esto, en el proyecto se dispusieron las diversas instalaciones para que en esta área no existiesen grandes estructuras, sino preferentemente zonas de manutención y almacenamiento de minerales, en las que las cargas son repartidas y los asientos tolerables relativamente grandes. Las estructuras, principalmente vigas carril de las grúas y canales para cintas transportadoras, se cimentaron sobre pilotes flotantes. De estos pilotes flotantes era preciso prever su capacidad de carga, pero también la magnitud de sus asientos reversibles, ya que las estructuras sobre ellos cimentadas habían de calcularse como estructuras hiperestáticas sobre apoyos elásticos. Para ello, además de los datos extraídos de los sondeos y de los ensayos de laboratorio, fué preciso hacer buen número de ensayos de carga sobre los pilotes hincados.

Es de hacer notar que la solución de pilotaje flotante en esta zona, aun teniendo en cuenta la naturaleza relativamente flexible de las estructuras

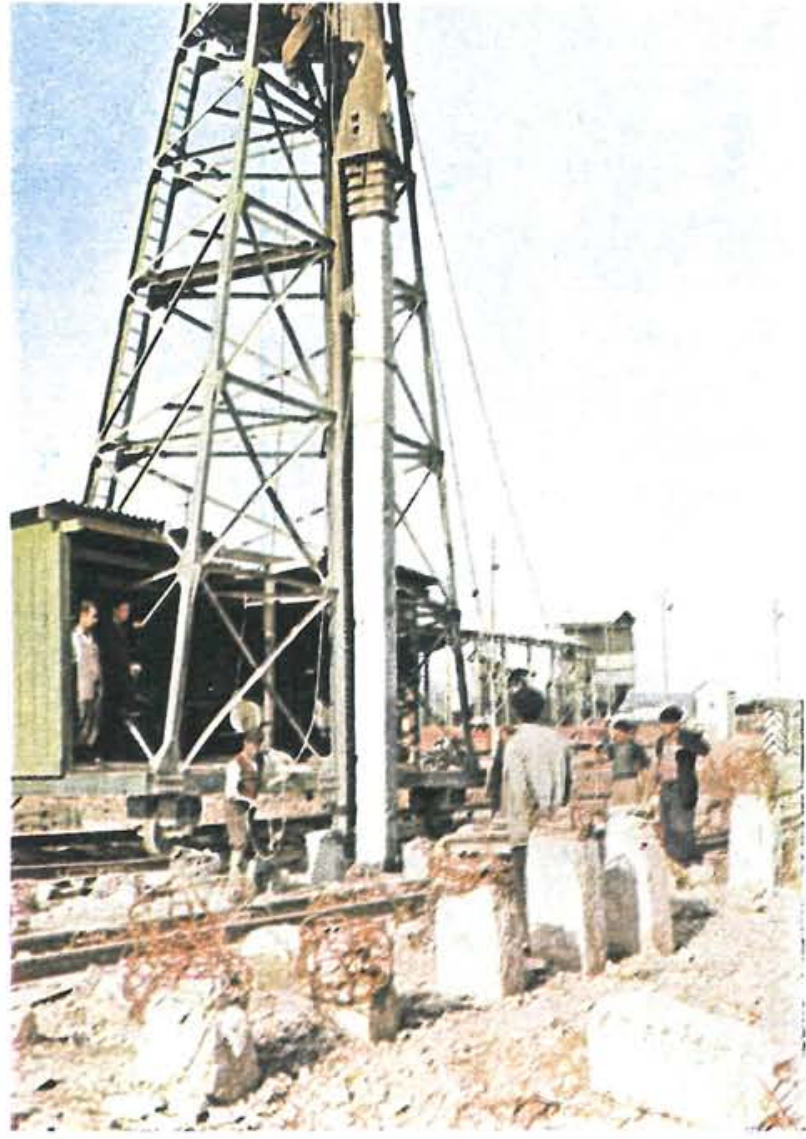

$820 \cdot 2$

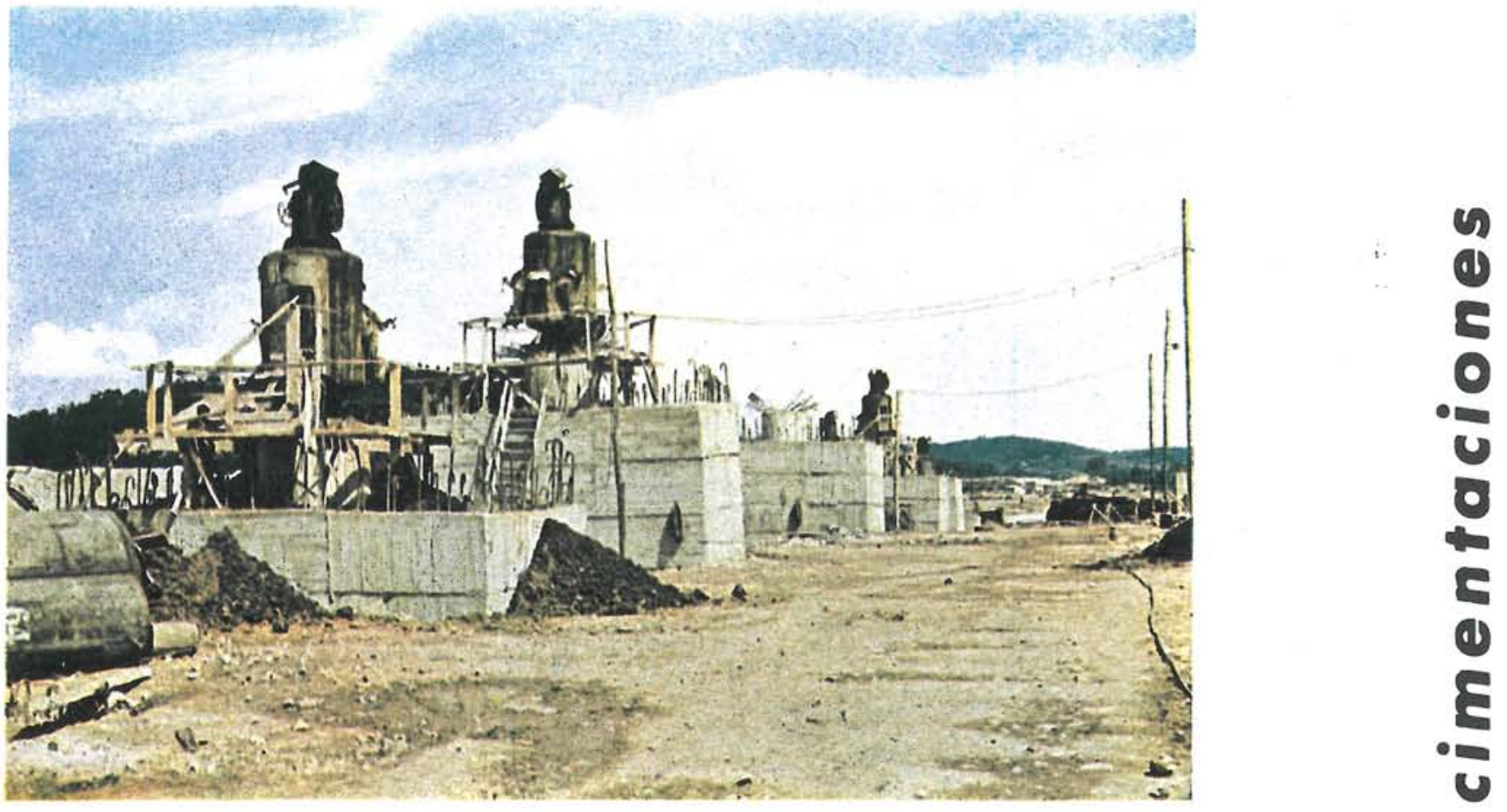



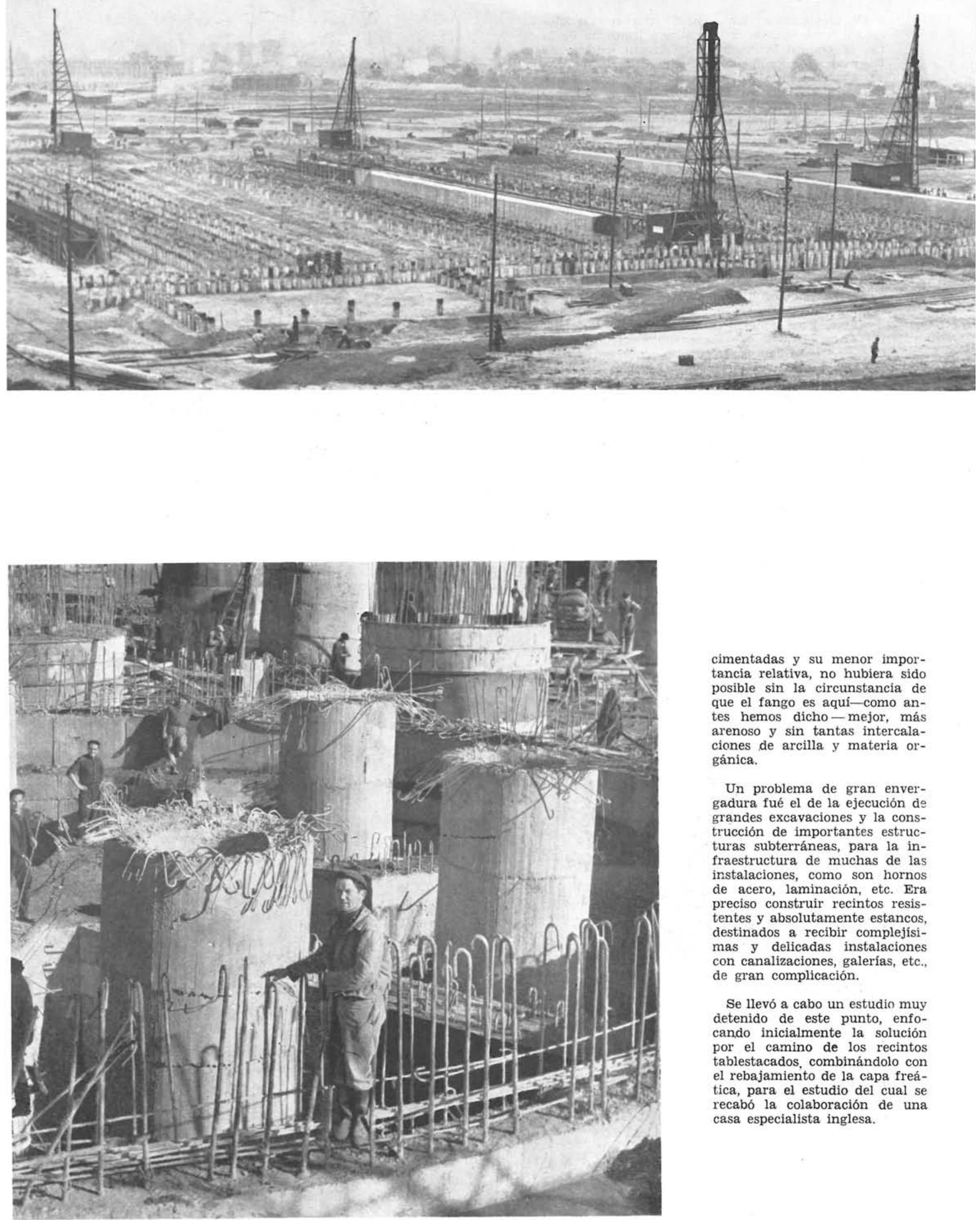

cimentadas y su menor importancia relativa, no hubiera sido posible sin la circunstancia de que el fango es aquí-como antes hemos dicho-mejor, más arenoso y sin tantas intercalaciones de arcilla y materia orgánica.

Un problema de gran envergadura fué el de la ejecución do grandes excavaciones y la construcción de importantes estructuras subterráneas, para la infraestructura de muchas de las instalaciones, como son hornos de acero, laminación, etc. Era preciso construir recintos resistentes y absolutamente estancos, destinados a recibir complejísimas y delicadas instalaciones con canalizaciones, galerías, etc. de gran complicación.

Se llevó a cabo un estudio muy detenido de este punto, enfocando inicialmente la solución por el camino de los recintos tablestacados combinándolo con el rebajamiento de la capa freática, para el estudio del cual se recabó la colaboración de una casa especialista inglesa. 

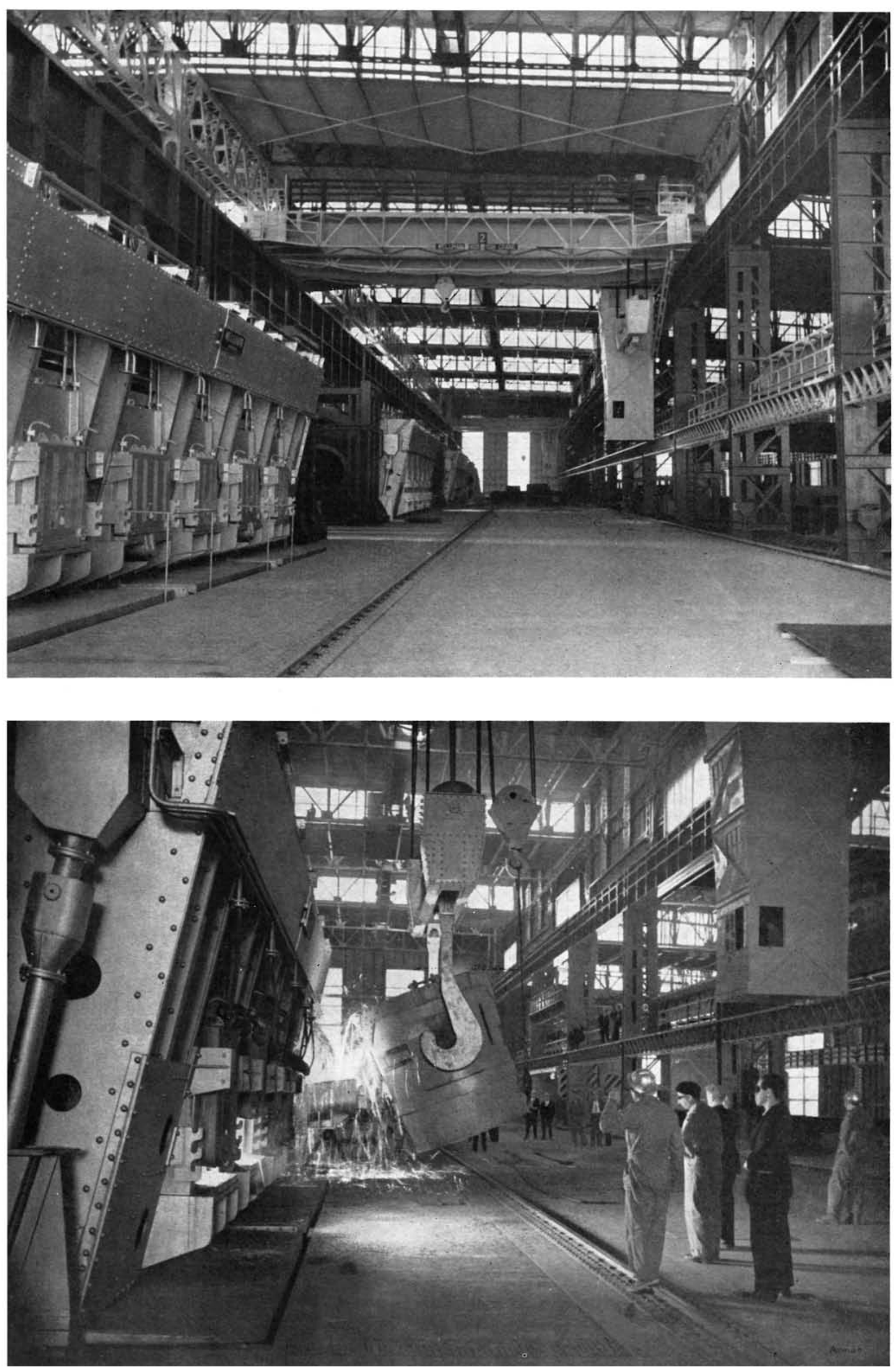


\section{hornos de acero}

Las instalaciones de hornos de acero "Siemens", de la Empresa Nacional Siderúrgica, están situadas al norte de la Factoría y, de tal manera, que el transporte del arrabio que procede de los hornos altos y que se transforma en acero en estas instalaciones se efectúe hasta las naves de laminación con arreglo a una circulación funcional sin que se produzca ningún retroceso.

En la primera fase, la acerería consta de un mezclador de $600 \mathrm{t}$, tres hornos basculantes de $300 \mathrm{t}$, y dos hornos fijos de 225 t. En ellos se realiza el afino del arrabio que procede de los hornos altos, añadiéndole chatarra, cal, caliza y mineral de hierro.

La producción total en esta primera etapa es del orden de $1.390 .000 \mathrm{t}$ de acero al año.

Las instalaciones constan de tres naves, todas de $318 \mathrm{~m}$ de longitud: nave de colada, nave de hornos y nave de almacenamiento.
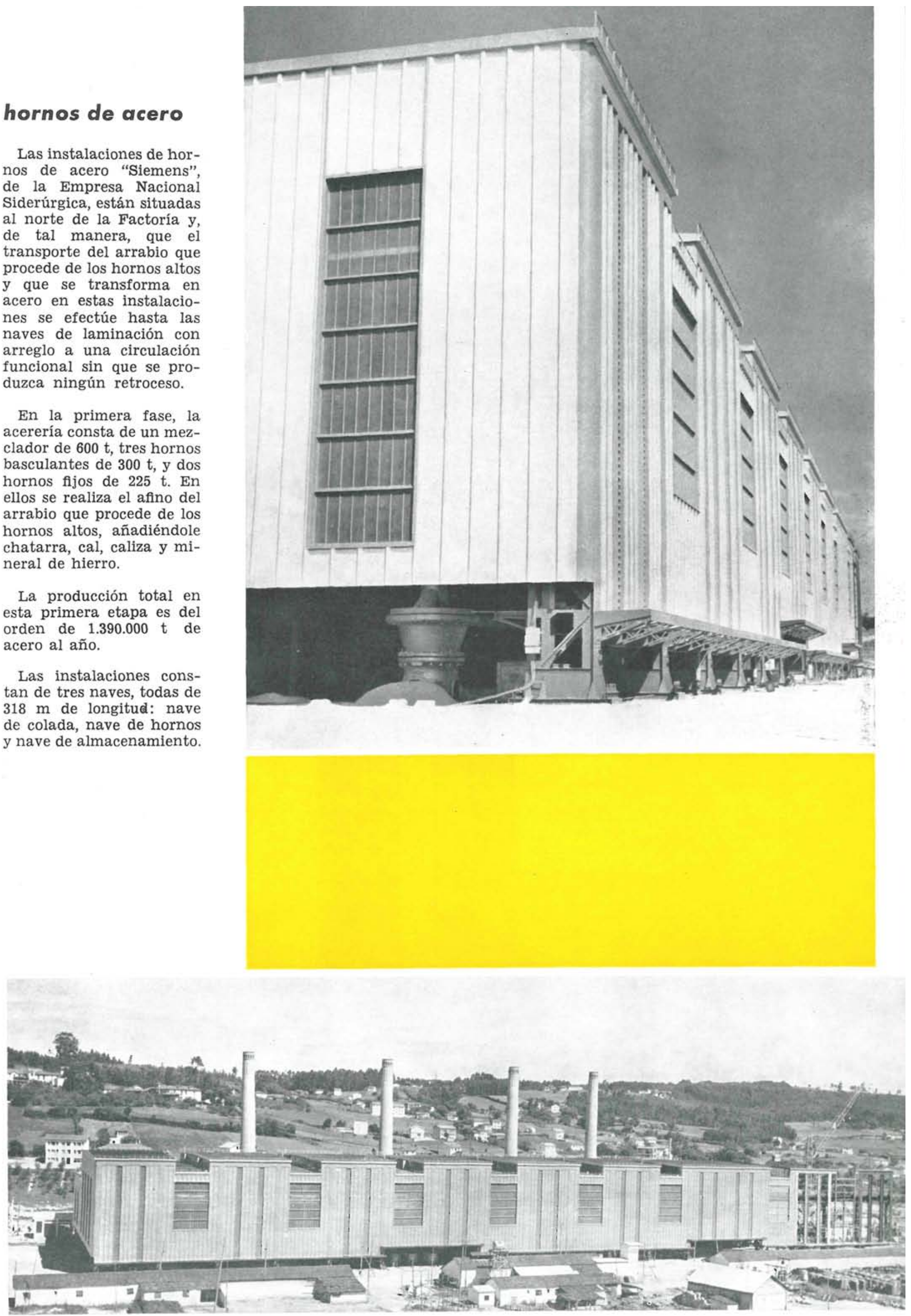


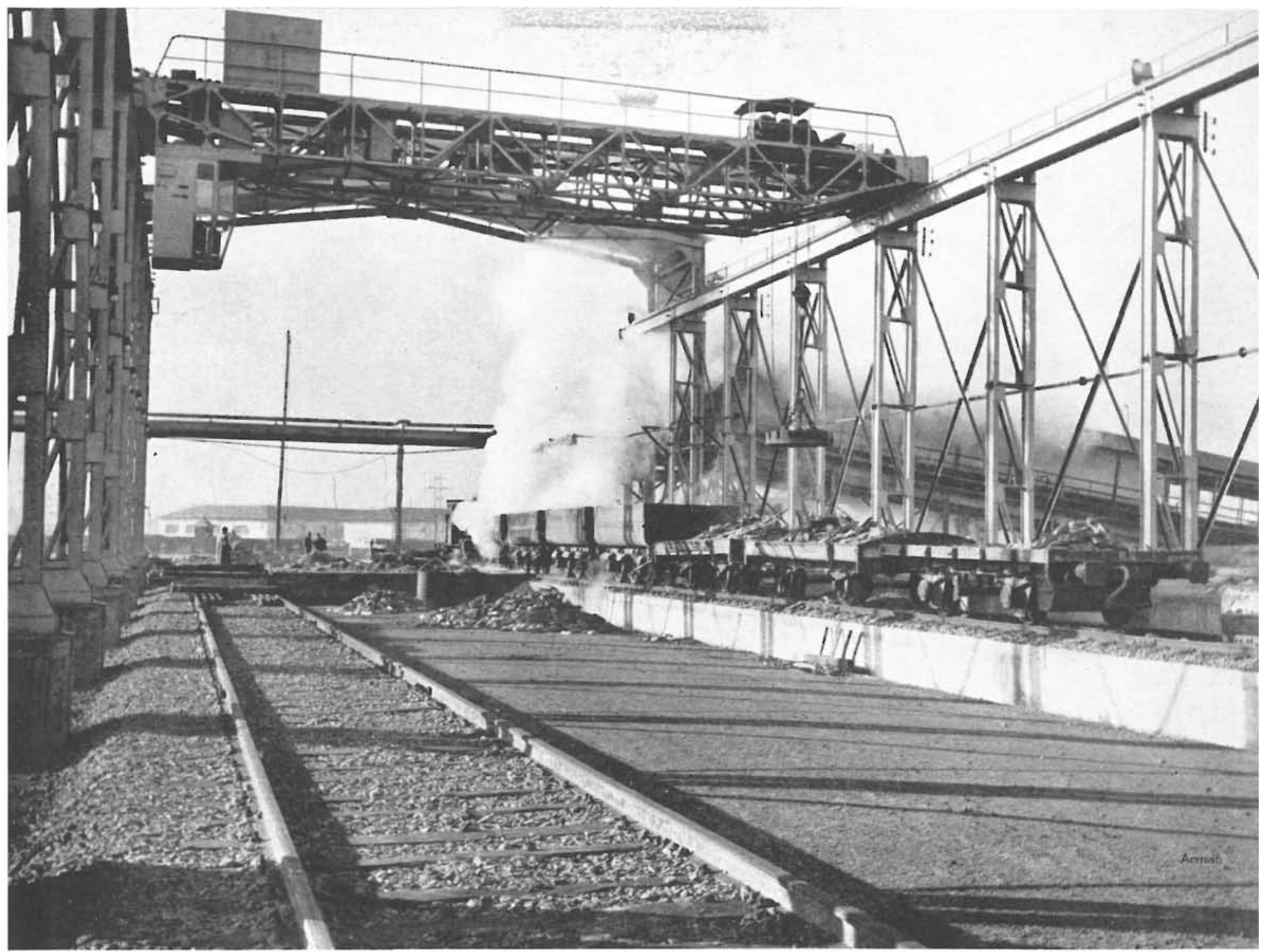

\section{generalidades}

La conyuntura económica de la época en la que se han realizado las obras de la Factoría de Avilés, caracterizada por la carencia de hierro en el mercado nacional y el gran coste del mismo, así como el propósito del Departamento de Obras Civiles de no importar más que los materiales estrictamente indispensables, tuvo como consecuencia que la gran mayoría de las instalaciones industriales y de los edificios que componen la Factoría se hayan realizado con estructura de hormigón armado.

Exclusivamente se hizo excepción a esta regla en aquellos casos en que, por razones funcionales, el empleo de estructuras metálicas era indispensable o cuando el realizar la obra en hormigón hubiera originado unos costes mucho más elevados.

De todas maneras, dada la envergadura de las obras realizadas, el gran número de instalaciones de la Factoría y su extraordinaria diversidad, son muchos los ejemplos de construcciones metálicas realizadas, pero sólo destacaremos las de hornos de acero y gasómetros que por su importancia y características ofrecen mayor interés. 